\title{
Isopimaric acid - a multi-targeting ion channel modulator reducing excitability and arrhythmicity in a spontaneously beating mouse atrial cell line
}

\author{
S. Salari, M. Silverå Ejneby, J. Brask and F. Elinder \\ Department of Clinical and Experimental Medicine, Linköping University, Linköping, Sweden
}

Received 22 February 2017 , revision requested 8 March 2017 , revision received 4 May 2017 , accepted 12 May 2017

Correspondence: F. Elinder, Division of Neurobiology, Department of Clinical and Experimental Medicine, Linköping University, SE-58। 85 Linköping, Sweden.

E-mail: fredrik.elinder@liu.se

See Editorial Commentary: $\mathrm{H}$. Ni, K. Narsingani, H. Zhang and W. R. Giles. 2017. Can principles of the surface potential be combined with knowledge of natural products to reduce atrial rhythm disturbances? Acta Physiol 222, el $29 \mid 8$.

\begin{abstract}
Aim: Atrial fibrillation is the most common persistent cardiac arrhythmia, and it is not well controlled by present drugs. Because some resin acids open voltage-gated potassium channels and reduce neuronal excitability, we explored the effects of the resin acid isopimaric acid (IPA) on action potentials and ion currents in cardiomyocytes.

Methods: Spontaneously beating mouse atrial HL-1 cells were investigated with the whole-cell patch-clamp technique.

Results: $1-25 \mu \mathrm{mol} \mathrm{L}^{-1}$ IPA reduced the action potential frequency by up to $50 \%$. The effect of IPA on six different voltage-gated ion channels was investigated; most voltage-dependent parameters of ion channel gating were shifted in the negative direction along the voltage axis, consistent with a hypothesis that a lipophilic and negatively charged compound binds to the lipid membrane close to the positively charged voltage sensor of the ion channels. The major finding was that IPA inactivated sodium channels and L- and T-type calcium channels and activated the rapidly activating potassium channel and the transient outward potassium channel. Computer simulations of IPA effects on all of the ion currents were consistent with a reduced excitability, and they also showed that effects on the $\mathrm{Na}$ channel played the largest role to reduce the action potential frequency. Finally, induced arrhythmia in the HL-1 cells was reversed by IPA.

Conclusion: Low concentrations of IPA reduced the action potential frequency and restored regular firing by altering the voltage dependencies of several voltage-gated ion channels. These findings can form the basis for a new pharmacological strategy to treat atrial fibrillation.

Keywords arrhythmia, atrial fibrillation, ion channels, isopimaric acid, patch clamp, resin acid.
\end{abstract}

Atrial fibrillation (AF) is the most common persistent cardiac arrhythmia in adults, which often leads to cardiac dysfunction and stroke. ${ }^{1,2}$ The main therapeutic strategies for AF are antiarrhythmic drugs. 3,4 However, current antiarrhythmic drugs can increase the risk of sudden death in patients recovering from myocardial infarction. ${ }^{5-8}$ Therefore, there is a need for safe and effective antiarrhythmic pharmaceuticals.
Clinical and in vivo studies have shown that polyunsaturated fatty acids (PUFAs) have protective effects against AF. ${ }^{9-11}$ PUFAs protect the cardiomyocytes by modulation of voltage-gated ion channels; they decrease the Na currents $\left(I_{\mathrm{Na}}\right)$, the Ca currents $\left(I_{\mathrm{Ca}}\right)$, the transient outward $\mathrm{K}$ current $\left(I_{\mathrm{to}}\right)$ and the rapidly activating K current $\left(I_{\mathrm{Kr}}\right)$ in cardiomyocytes. Our laboratory has recently shown that PUFAs modulate voltage-gated ion 
channels via an electrostatic mechanism; the polyunsaturated acyl chain of the PUFAs is needed to place the carboxyl group near the voltage sensor of the channel, and the charged carboxyl group electrostatically interacts with gating charges in the voltage sensor. ${ }^{12-17}$ However, despite their positive effects, the highly flexible PUFA molecules bind to numerous biological targets and are thus less likely to be developed into pharmaceuticals. Therefore, it is imperative to search for small-molecule compounds with channel-modulating properties similar to the PUFAs.

Resin acids constitute a mixture of several related carboxylic acids found in tree resins, used to produce soaps for diverse applications. ${ }^{18,19}$ Pimaric acid and isopimaric acid (IPA), common resin acids in pine rosin, open the big-conductance $\mathrm{K}\left(\mathrm{BK}_{\mathrm{Ca}}\right)$ channel, ${ }^{20}$ decrease spike and burst frequency in rat brain neurones and can prevent epilepsy ${ }^{21,22}$ and reduce the action potential amplitude in pancreatic $\beta$ cells. ${ }^{23} \mathrm{BK}_{\mathrm{Ca}}$ channels are not expressed in cardiomyocytes, ${ }^{24}$ and consequently, these compounds should not affect cardiomyocytes. However, we have recently shown that several resin acids modulate a voltage-gated $\mathrm{K}$ channel via an electrostatic mechanism, in a similar fashion as do PUFAs, ${ }^{16,25}$ and thus, it is possible that these compounds also affect cardiac ion channels and cardiac excitability.

The HL-1 cell line from the mouse is an excellent model to study atrial cardiomyocytes in vitro ${ }^{26}$; the cells in this line are spontaneously beating and have typical atrial ion currents including $I_{\mathrm{Na}}, I_{\mathrm{to}}, I_{\mathrm{Kr}}$, the L-type Ca current $\left(I_{\mathrm{Ca}(\mathrm{L})}\right)$, the T-type Ca current $\left(I_{\mathrm{Ca}(\mathrm{T})}\right)$ and the pace-maker hyperpolarization-activated non-selective cation current $\left(I_{\mathrm{f}}\right)^{27-29}$ Thus, considering the possible functional similarity between IPA, pimaric acid and PUFAs, we thereby aimed to investigate pimaric acid and IPA effects on the electrical activity of HL-1 cells.

\section{Results}

\section{Low concentrations of IPA reduced the pace in HL-I cells}

Whole-cell current-clamp recordings were carried out on spontaneously firing HL-1 cells, before and after the application of 1, 10 (Fig. 1a), 25 and $50 \mu \mathrm{mol} \mathrm{L}{ }^{-1}$ IPA. Standard action potential parameters were measured in control solution from 30 cells $(1 \mathrm{~min}$ recording in each cell): The firing frequency was $2.7 \pm 0.3 \mathrm{~Hz}$, the resting membrane potential (RMP) was $-61.4 \pm 0.7 \mathrm{mV}$, the action potential amplitude was $82.3 \pm 2.5 \mathrm{mV}$, the maximum rising slope was $31.8 \pm 7.1 \mathrm{mV} \mathrm{ms}^{-1}$, the maximum decay slope was $-6.0 \pm 1.5 \mathrm{mV} \mathrm{ms}^{-1}$, and the $\mathrm{APD}_{30}, \mathrm{APD}_{50}$ and $\mathrm{APD}_{90}$ were $24.2 \pm 2.6 \mathrm{~ms}$, $35.7 \pm 2.9 \mathrm{~ms}$ and $84.2 \pm 5.9 \mathrm{~ms}$ respectively. The effects of $1,10,25$ and $50 \mu \mathrm{mol} \mathrm{L}{ }^{-1}$ IPA on the mentioned parameters relative the controls are shown in
Figure 1b-i. Most significantly, IPA reduced the action potential frequency at 1,10 and $25 \mu \mathrm{mol} \mathrm{L}^{-1}$ with no significant effect at $50 \mu \mathrm{mol} \mathrm{L}{ }^{-1}$ dose (Fig. 1b). The reduction at 10 and $25 \mu \mathrm{mol} \mathrm{L}^{-1}$ was close to $50 \%$. IPA had no effect on the cardiomyocytes' resting membrane potential (Fig. 1c) and only a small effect on the action potential amplitude at $50 \mu \mathrm{mol} \mathrm{L}^{-1}$ (Fig. 1d). With respect to the time course of the action potential (Fig. 1e-i), $1 \mu \mathrm{mol} \mathrm{L}{ }^{-1}$ significantly sped up the maximum slope decay and made the action potential shorter (reduced $\mathrm{APD}_{30}$ and $\mathrm{APD}_{50}$ ). 10 and $25 \mu \mathrm{mol} \mathrm{L}{ }^{-1} \mathrm{IPA}$ had no effect on the time course. $50 \mu \mathrm{mol} \mathrm{L}^{-1}$ IPA slowed down both the rising phase and decay phase, thus yielding a longer action potential at the base $\left(\mathrm{APD}_{90}\right)$. To summarize, IPA had an effect on the action potential frequency at the lowest concentration investigated $\left(1 \mu \mathrm{mol} \mathrm{L}{ }^{-1}\right)$ and a highly pronounced effect at 10 and $25 \mu \mathrm{mol} \mathrm{L}^{-1}$, while leaving most other measured parameters unaffected. At $50 \mu \mathrm{mol} \mathrm{L}{ }^{-1}$, there was no effect on the action potential frequency. This suggests potentially therapeutic effects in the concentration range $1-10 \mu \mathrm{mol} \mathrm{L}{ }^{-1}$. There is no need to increase the concentration, with increased risk of side effects, because higher concentrations had similar or less pronounced effects on the action potential frequency. We also tested the effect of pimaric acid (only differing in the position of one double bond compared to IPA) on the action potential frequency. However, the effect was less pronounced; $10 \mu \mathrm{m}$ pimaric acid reduced the action potential frequency only by $15 \pm 1 \%(n=4)$ compared to $47 \pm 11 \%$ for IPA. Thus, in the remainder of this work, we focused on IPA. To explore the underlying effects, on the ion channel level, we investigated the effects of IPA on six different ion currents, separately, using whole-cell voltage-clamp recordings.

\section{IPA promoted inactivation of the sodium current ( $\left.\mathrm{I}_{\mathrm{Na}}\right)$}

Typical $I_{\mathrm{Na}}$ voltage-clamp families, measured in response to voltage steps between -80 and $+20 \mathrm{mV}$ from a holding voltage of $-120 \mathrm{mV}$, are shown in control and after applying 1, 10 and $50 \mu \mathrm{mol} \mathrm{L}{ }^{-1}$ IPA respectively (Fig. 2a-d). Only $50 \mu \mathrm{mol} \mathrm{L}^{-1}$ IPA significantly reduced the maximum peak amplitude of $I_{\mathrm{Na}}$ vs. voltage $\left(I_{\mathrm{Na}}(V)\right)$ relations (Fig. 2e; $n=8$ cells, $P<0.05)$. All concentrations of IPA significantly shifted $G_{\mathrm{Na}}(V)$ and the steady-state inactivation curve in negative direction along the voltage axis (Fig. $2 \mathrm{f}-\mathrm{h}$ ). The IPA-induced shifts for $G_{\mathrm{Na}}(V)$ were $-4.4 \pm 0.7$, $-6.1 \pm 0.6$ and $-5.2 \pm 1.1 \mathrm{mV}$ respectively, but no significant difference was found between different IPA doses (Fig. 2h). The IPA-induced shifts of the steadystate inactivation curve were $-5.8 \pm 0.6,-9.0 \pm 1.6$ and $-12.8 \pm 1.8 \mathrm{mV}$ respectively. The IPA-induced shift for $50 \mu \mathrm{mol} \mathrm{L}{ }^{-1}$ was significantly larger than for 
(a)

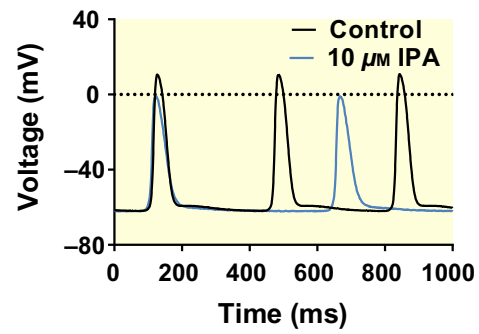

(d)

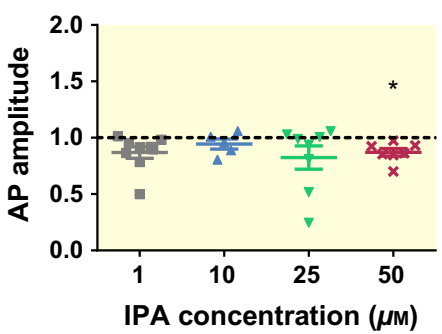

(g)

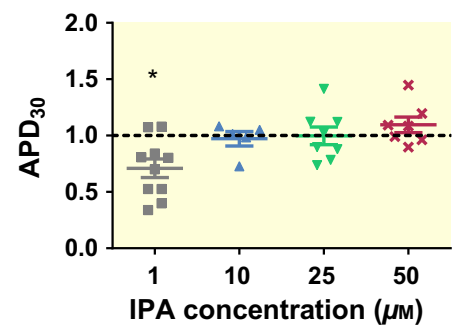

(b)

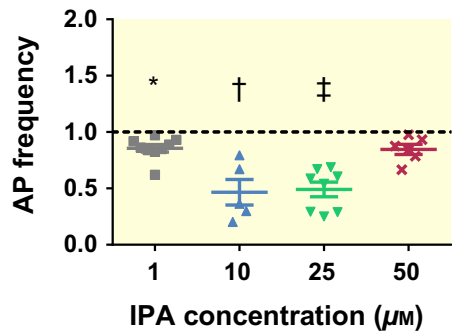

(e)

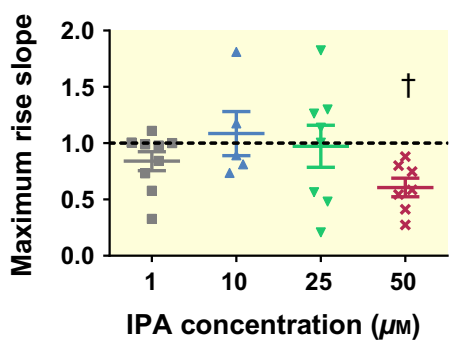

(h)

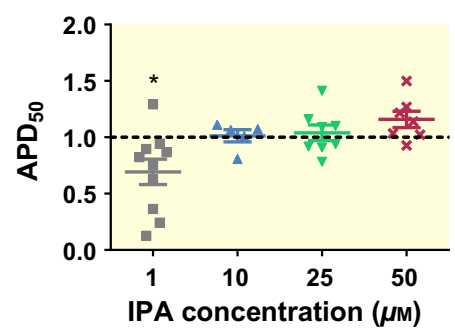

(c)

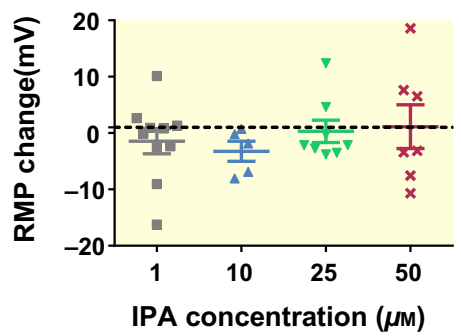

(f)

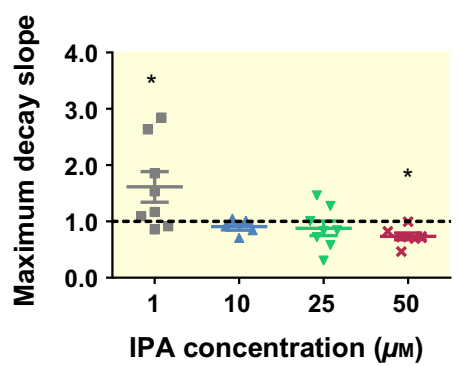

(i)

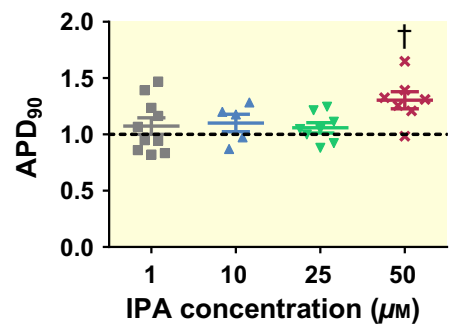

Figure I IPA effect on spontaneous action potentials in HL-1 cells. (a) $10 \mu \mathrm{M}$ IPA reduced the frequency. (b-i) Summary of the IPA effects on action potential parameters. All panels except for $(c)$ show the parameters relative control. Data are expressed as mean \pm SEM, and the signs at the symbols indicate significant differences between control and IPA $(n=30$ cells; $* P<0.05$;

$\left.{ }^{\dagger} P<0.01 ;{ }^{\star} P<0.001\right)$.

$1 \mu \mathrm{mol} \mathrm{L}{ }^{-1}$ (Fig. 2h). IPA significantly and dose dependently increased the time to recover from inactivation (Fig. 2i-j). IPA had a larger effect on the late steadystate $I_{\mathrm{Na}}$ than on the early peak $I_{\mathrm{Na}} ; 10$ and $50 \mu \mathrm{mol} \mathrm{L}{ }^{-1}$ IPA significantly reduced the current measured at $15 \mathrm{~ms}$ after the onset of the voltage-clamp pulse (Fig. 2k). To summarize the effects on $I_{\mathrm{Na}}$, $1 \mu \mathrm{mol} \mathrm{L}{ }^{-1}$ IPA affected all measured $\mathrm{Na}$ channel parameters except for the peak current. At higher doses, the effects on inactivation were more pronounced than those on activation.

\section{IPA increased the transient outward potassium current $\left(\mathrm{I}_{t o}\right)$}

Typical $I_{\text {to }}$ traces before and after IPA application are shown in Figure 3a-d. 1 and $10 \mu \mathrm{mol} \mathrm{L}{ }^{-1}$ IPA significantly increased the current at $10-60 \mathrm{mV}$ (Fig. 3e). IPA did not shift $G_{\text {to }}(V)$ along the voltage axis, but the steady-state inactivation curve was significantly and dose dependently shifted (Fig. 3f-h). To summarize, IPA significantly increased the peak current by $30 \%$ at 1 and $10 \mu \mathrm{mol} \mathrm{L}^{-1}$ and shifted the steadystate inactivation curve in the negative direction while leaving the activation $\left(G_{\text {to }}(V)\right)$ unaffected.

\section{IPA opened the rapidly activating delayed-rectifier potassium current $\left(\mathrm{I}_{K_{r}}\right)$}

In the presence of nifedipine to block $I_{\mathrm{Ca}(\mathrm{L})}$, and holding the potential at $-50 \mathrm{mV}$ to block $I_{\mathrm{Na}}$ and $I_{\mathrm{Ca}(\mathrm{T})}$, the HL-1 cells showed outward currents at voltages between -30 and $60 \mathrm{mV}$ and an outward tail current at $-20 \mathrm{mV}$ (Fig. 4a). All currents were almost completely blocked by $1 \mu \mathrm{mol} \mathrm{L}{ }^{-1}$ of the $I_{\mathrm{Kr}}$ blocker E4031 (Fig. 4b). $1 \mu \mathrm{mol} \mathrm{L}{ }^{-1}$ IPA increased $I_{\mathrm{Kr}}$ between -20 and $30 \mathrm{mV}$ and 10 and $50 \mu \mathrm{mol} \mathrm{L}{ }^{-1}$ IPA increased $I_{\mathrm{Kr}}$ at $-20 \mathrm{mV}$, while leaving the maximum 
(a)

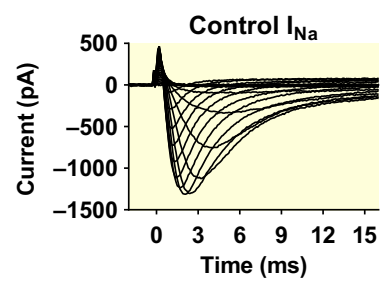

(e)

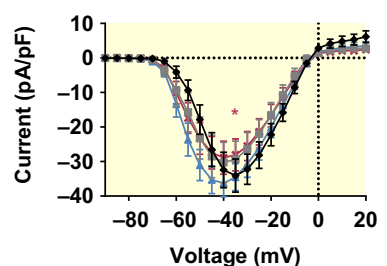

(i)

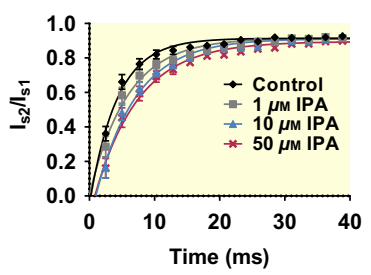

(b)

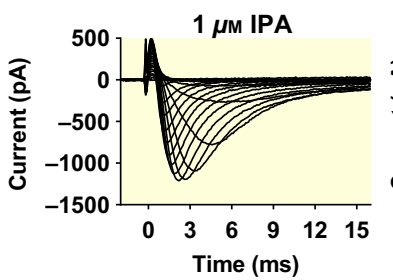

(f)

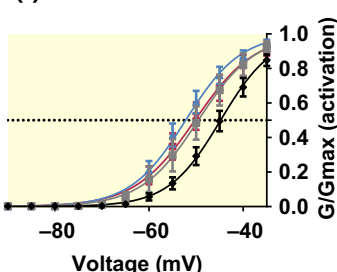

(j)

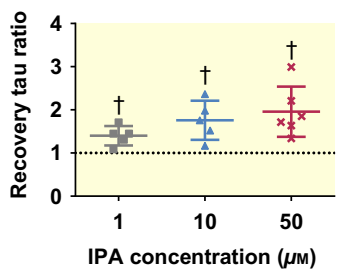

(c)

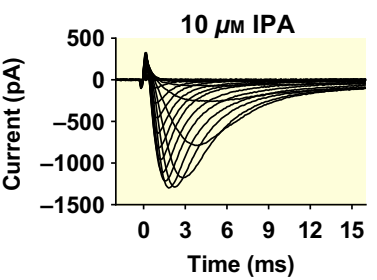

(g)

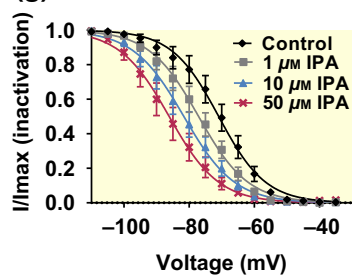

(k)

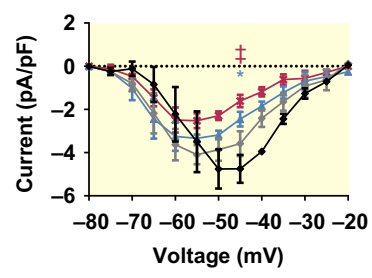

(d)
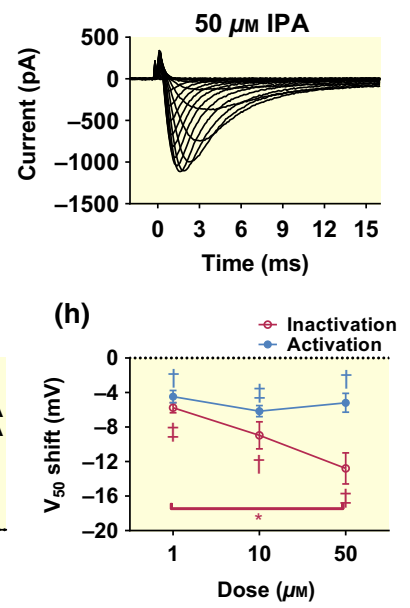

Figure 2 IPA effect on the Na current $\left(I_{\mathrm{Na}}\right)$. (a-d) Typical $I_{\mathrm{Na}}$ traces before and after application of different concentrations of IPA. Currents were measured at voltages between -110 and $0 \mathrm{mV}$, in increments of $5 \mathrm{mV}$, from a holding voltage of $-120 \mathrm{mV}$.

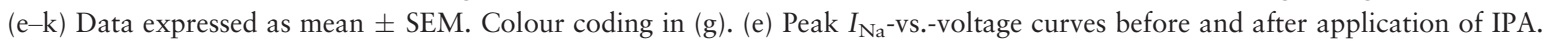
'*' denotes significant differences between $50 \mu \mathrm{mol} \mathrm{L}{ }^{-1}$ and control $(n=8 ; P<0.05)$. (f) Peak Na conductance-versus-voltage curves before and after application of IPA $(n=8)$. Data fitted to Eq. 2. (g) Steady-state inactivation curves were plotted by normalizing the peak currents at $-10 \mathrm{mV}$, following conditioning pulses of $500 \mathrm{~ms}$ to voltages between $-110 \mathrm{mV}$ and 0 in $5 \mathrm{mV}$ increments, from a holding voltage of $-120 \mathrm{mV}(n=8)$. Data fitted to Eq. 2. (h) Summary of IPA-induced shifts from (f) and (g). The signs at the symbols indicate data significantly different from 0 . The '*'-sign at the line indicates a significant difference between 1 and $50 \mu \mathrm{mol} \mathrm{L}{ }^{-1} \mathrm{IPA}\left(* P<0.05 ;{ }^{\dagger} P<0.01 ;{ }^{\ddagger} P<0.001\right)$. (i) Recovery from inactivation. Standard double pulse protocol, with a holding voltage of $-120 \mathrm{mV}$ and a test pulse to $-30 \mathrm{mV}$ for $20 \mathrm{~ms}$ with different inter-pulse interval durations $(\Delta t)$, was used $(n=5)$ and fitted to single exponential curves. (j) Time constants from (i). Signs at the symbols indicate data significantly different from $1\left({ }^{\dagger} P<0.01\right)$. (k) $I_{\mathrm{Na}}$ at $15 \mathrm{~ms}$ after applying different voltages, before and after IPA application in different doses. Signs indicate significant differences between IPA groups and control $\left(n=4 ; * P<0.05 ;{ }^{\star} P<0.001\right)$.

tail current unaffected (Fig. $4 \mathrm{c}-\mathrm{d}$ ). The $G_{\mathrm{Kr}}(V)$ curve was significantly shifted (at all concentrations) in the negative direction along the voltage axis, while the steady-state inactivation curve was not significantly affected (Fig. 4e-g). In addition, IPA significantly and dose dependently sped up the activation time course (Fig. $4 \mathrm{~h}-\mathrm{i}$ ). To summarize the effects on $I_{\mathrm{Kr}}$, IPA lead to faster opening and opening at more negative voltages (significant effects were already present at $1 \mu \mathrm{mol} \mathrm{L}^{-1}$ ) while the steady-state inactivation was unaffected.

\section{IPA reduced the $L$ and T-type calcium currents by promoting inactivation}

Low concentrations of IPA clearly and dose dependently reduced $I_{\mathrm{Ca}(\mathrm{L})}$ (Fig. 5a-d); $1 \mu \mathrm{mol} \mathrm{L}^{-1}$ IPA reduced the peak current measured at $0 \mathrm{mV}$ by
$53 \pm 13 \%$ (Fig. 5e). IPA also clearly shifted the (normalized) $G_{\mathrm{Ca}(\mathrm{L})}(V)$ and the steady-state inactivation curves in the negative direction along the voltage axis, steady-state inactivation more than activation $\left(G_{\mathrm{Ca}}\right.$ (L) $(V))$, and the effects were saturated already at $1 \mu \mathrm{mol} \mathrm{L}{ }^{-1}$ IPA (Fig. 5e-h). However, the exact size of the shift for the steady-state inactivation curve was difficult to estimate because we could not determine whether the effect was an isolated shift or whether it was a shift in combination with a voltage-independent reduction of the current. Non-normalized data are presented (Fig. $5 \mathrm{~g}$ ), but the shifts were determined from normalized steady-state inactivation curves, thus representing a lower estimate (Fig. 5h). It should be noted that a shift of the activation curve is counteracted by the reduction in current (Fig. 5e), and thus, IPA does not lead to opening of the channel despite 
(a)

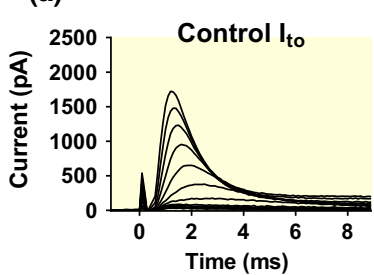

(e)

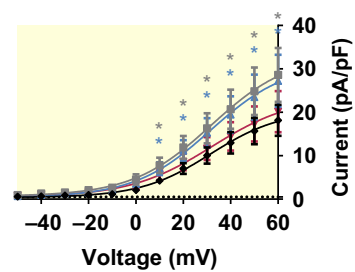

(b)

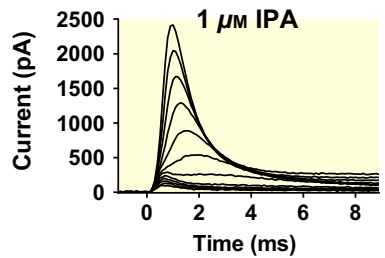

(f)

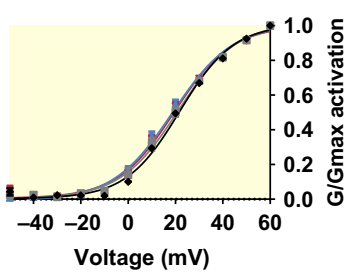

(c)

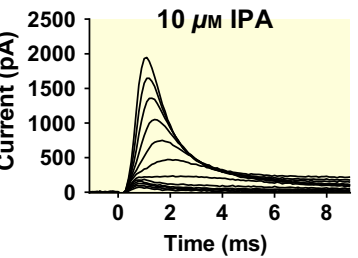

(g)

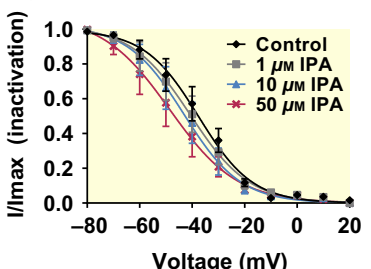

(d)

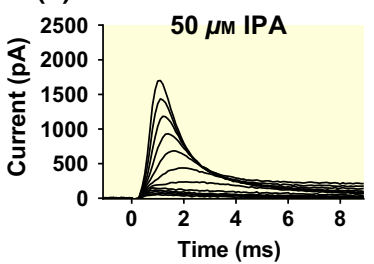

(h)

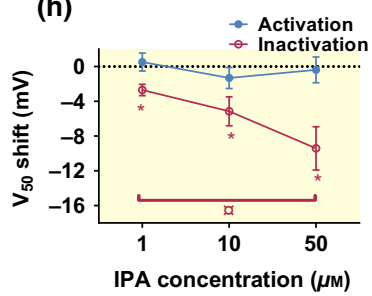

Figure 3 IPA effect on the transient outward K current $\left(I_{\text {to }}\right)$. (a-d) Typical $I_{\text {to }}$ traces before and after application of different IPA concentrations. Currents evoked by voltage steps between -50 and $+60 \mathrm{mV}$ in $10 \mathrm{mV}$ increments. Holding voltage was $-80 \mathrm{mV}$. (e-h) Data expressed as mean \pm SEM. Colour coding in (g). (e) Peak $I_{\text {to }}$-vs.-voltage curves before and after application of IPA. '** indicates significant difference from control $(n=6 ; P<0.05)$. (f) Peak K conductance-vs.-voltage curves before and after application of IPA $(n=6)$. Data fitted to Eq. 2. (g) Steady-state inactivation curves were plotted by normalizing the peak currents at $+40 \mathrm{mV}$, following conditioning pulses of $500 \mathrm{~ms}$ to voltages between $-80 \mathrm{mV}$ and +20 in $10 \mathrm{mV}$ increments, from a holding voltage of $-80 \mathrm{mV}(n=6)$. Data fitted to Eq. 2. (h) Summary of IPA-induced shifts from (f) and (g). '*' signs at the symbols indicate significant differences from 0 . The ' $\mathrm{Q}$ '-sign at the line indicates a significant difference between 1 and $50 \mu \mathrm{mol} \mathrm{L}{ }^{-1} \mathrm{IPA}\left({ }^{*} P<0.05\right)$.

the leftward shift. $I_{\mathrm{Ca}(\mathrm{T})}$ was dose dependently sensitive to IPA (Fig. 6a-e), but to reduce the peak current, higher concentrations than for $I_{\mathrm{Ca}(\mathrm{L})}$ were needed: $10 \mu \mathrm{mol} \mathrm{L}^{-1}$ reduced the current at $-35 \mathrm{mV}$ by $40 \pm 8 \%$. IPA significantly and dose dependently shifted the normalized $G_{\mathrm{Ca}(\mathrm{T})}(V)$ (Fig. 6f) and the steady-state inactivation (Fig. 6g) curves in negative direction along the voltage axis, inactivation more than twice that of the activation (Fig. 6h). To summarize, both $I_{\mathrm{Ca}(\mathrm{L})}$ and $I_{\mathrm{Ca}(\mathrm{T})}$ are highly sensitive to IPA; the steady-state inactivation curves are more affected than the activation, $G(V)$, curves which leads to a clear reduction in the currents.

\section{IPA had no effect on the pace-maker current (l $\left.\mathrm{l}_{f}\right)$}

The pace-maker current $I_{\mathrm{f}}$ makes the HL-1 cells beat spontaneously. Typical $I_{\mathrm{f}}$ traces are shown in Figure $7 \mathrm{a}, \mathrm{b}$, before and after application of $50 \mu \mathrm{mol} \mathrm{L} \mathrm{L}^{-1}$ IPA. It should be noted that $I_{\mathrm{f}}$ could not be detected in all HL-1 cells. IPA did not significantly alter the current or the voltage dependence of $\mathrm{I}_{\mathrm{f}}$ (Fig. $7 \mathrm{c}-\mathrm{e}$ ), and thus, the IPA effect on the action potential firing is most likely not caused by an effect on the pacemaker channel.

\section{Computer simulations}

To explore whether the found effects of IPA on $I_{\mathrm{Na}}$, $I_{\mathrm{to}}, I_{\mathrm{Kr}}, I_{\mathrm{Ca}}$ are sufficient to understand the effect on action potential firing, we implemented the effects in a computer model of electrical activity in a spontaneously beating cardiomyocyte. In the absence of a functioning HL-1 cell model, we used a spontaneously beating Purkinje fibre cell model. Even though the sets of ion channels do not entirely overlap, most channels do, and we believe that the simulations can give at least semi-quantitative information. First, we explored the effect channel by channel. Altering $I_{\mathrm{Na}}$ according to our experimental data, we found a clear reduction in firing frequency at 1 and $10 \mu \mathrm{mol} \mathrm{L}^{-1}$, with a smaller reduction at $50 \mu \mathrm{mol} \mathrm{L}^{-1}$ (Fig. 8a-e). This fits well with experimental data. Altering $I_{\mathrm{Ca}(\mathrm{L})}$ we found a reduced firing frequency but the effects were less pronounced (Fig. 8f). Altering $I_{\mathrm{Kr}}$ or $I_{\text {to }}$ had essentially no effect on the frequency $(<1 \%)$. $I_{\mathrm{Ca}(\mathrm{T})}$ was not present in the model, so this could not be tested. In the last step, we introduced all alterations simultaneously (Fig. 8g,h). $1 \mu \mathrm{mol} \mathrm{L}{ }^{-1}$ reduced the frequency by $69 \%$. $10 \mu \mathrm{mol} \mathrm{L}^{-1}$ prevented spontaneous activity and $50 \mu \mathrm{mol} \mathrm{L}^{-1}$ IPA reduced the frequency by $42 \%$. Thus, the effects in the model were more pronounced than in the experiments, but qualitatively, the effects matched the concentrations, with the largest effects at $10 \mu \mathrm{mol} \mathrm{L}{ }^{-1}$ and the smallest at $50 \mu \mathrm{mol} \mathrm{L}^{-1}$. The reason for this quantitative difference most likely has to do with the fact that the published model we used does not exactly match the HL-1 cells we studied. 
(a)

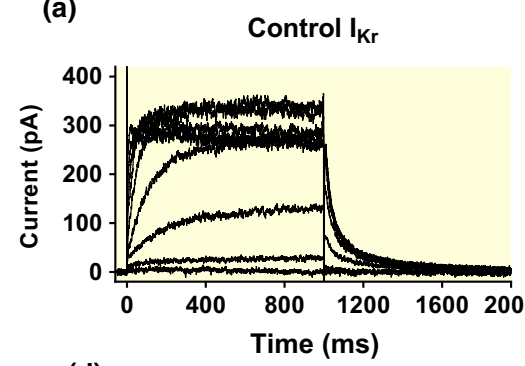

(d)

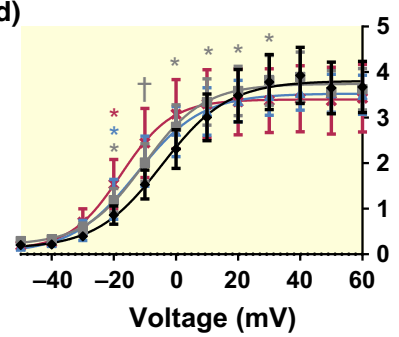

(g)

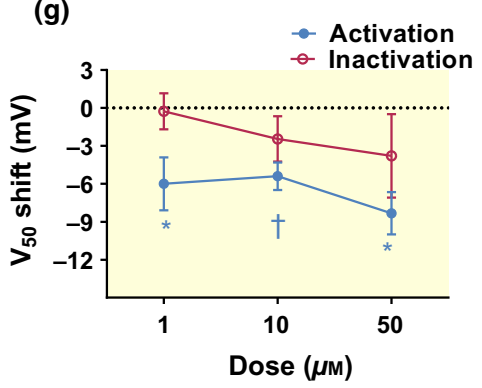

(b)

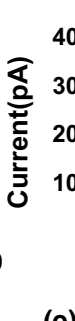

(e)

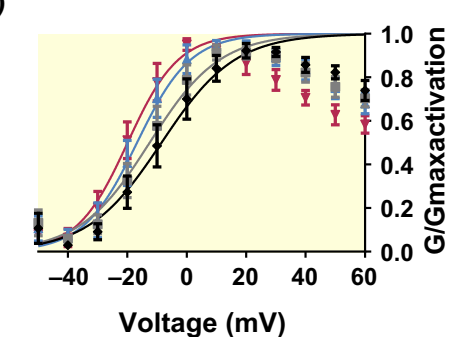

(h)

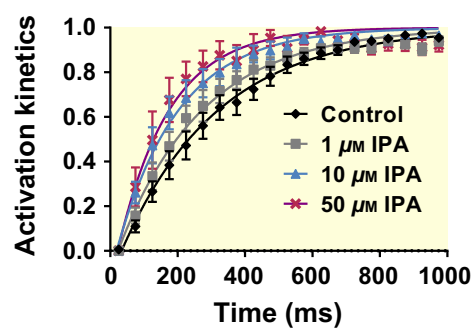

(c)
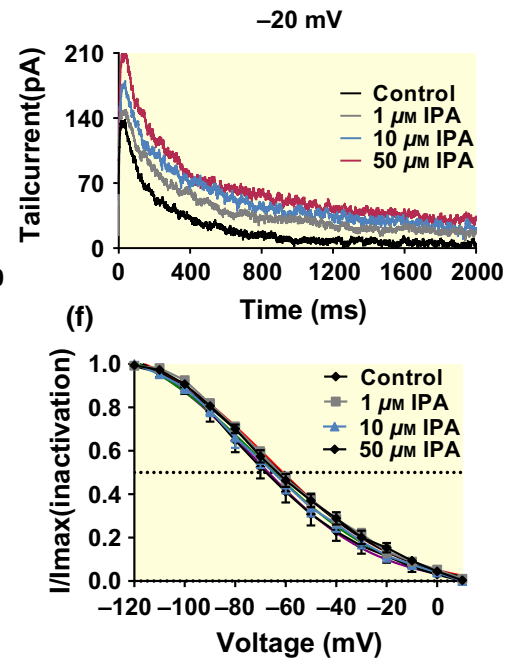

(i)

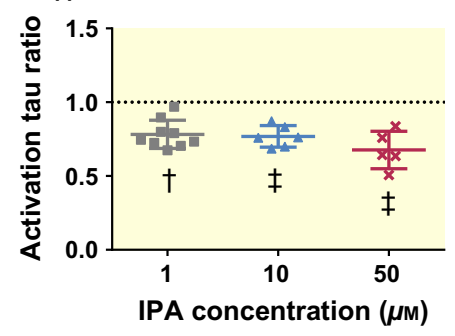

Figure 4 IPA effect on the rapidly activating delayed-rectifier $\mathrm{K}$ current $\left(I_{\mathrm{Kr}}\right)$. (a, b) Typical current traces are shown before and after application of $1 \mu \mathrm{mol} \mathrm{L}{ }^{-1}$ of the specific $I_{\mathrm{Kr}}$ channel blocker E4031. The current traces were elicited by voltage steps to $60 \mathrm{mV}$ from a holding voltage of $-50 \mathrm{mV}$. (c) $I_{\mathrm{Kr}}$ tail currents at $-20 \mathrm{mV}$ before and after applying IPA in different concentrations. ( $\mathrm{d}-\mathrm{i}$ ) Data expressed as mean \pm SEM. Colour coding in (f). (d) Tail current amplitude-vs.-voltage curves before (mean of controls includes the control from all different IPA concentrations) and after application of IPA. Signs indicate significant differences from control $\left(n=5-9\right.$; $\left.{ }^{*} P<0.05 ;{ }^{\dagger} P<0.01\right)$. Data fitted to Eq. 2. (e) Normalized data from (d). (f) Steady-state inactivation was plotted by normalizing the tail currents which were induced with a three-pulse protocol. (i) A 1-s voltage pulse was applied to $+20 \mathrm{mV}$ from a holding voltage of $-50 \mathrm{mV}$ to activate and inactivate the channels. (ii) This was followed by 10 -ms steps between -120 and $10 \mathrm{mV}$ to recover the channels from inactivation. (iii) Finally, a voltage step to $+20 \mathrm{mV}$ was used as test potential $(n=5-9)$. Data fitted to Eq. 2. (g) Summary of IPA-induced shifts from (e) and (f). Signs at the symbols indicate significant differences from $0\left(n=5-9 ; * P<0.05 ;{ }^{\dagger} P<0.01\right)$. (h) Activation kinetics before and after IPA application. Plotted by normalizing $I_{\mathrm{Kr}}$ tail currents which were elicited by a pulse to $+20 \mathrm{mV}$ from $-50 \mathrm{mV}$ holding voltage with different pulse durations $(n=5-9)$ and fitted to single exponential curves. (i) Time-constant changes relative control. Signs at the symbols indicate significant differences from $1\left(n=5-9 ; * P<0.05 ;{ }^{\dagger} P<0.01 ;{ }^{\star} P<0.001\right)$.

\section{IPA normalized pharmacologically induced cardiac arrhythmia}

There is no suitable pharmacological model for inducing $\mathrm{AF}$ in cultured cardiomyocytes. Jahangiri et al. ${ }^{9}$ used a combination of electrical synchronous stimulation and application (for seven minutes) of $10 \mu \mathrm{mol} \mathrm{L}^{-1}$ isoproterenol (ISO) to induce asynchronous contraction in single atrial cardiomyocytes. We tried $10 \mu \mathrm{mol} \mathrm{L}^{-1}$ ISO to induce arrhythmia without applying electrical stimulation, because confluent HL-1 cells beat spontaneously. $10 \mu \mathrm{mol} \mathrm{L}^{-1}$
ISO increased the action potential frequency in the HL-1 cells, but no irregularity was detected in the pattern of action potentials even after $12 \mathrm{~min}$ of ISO application (Fig. S1). Because cardiomyocytes are connected to each other and work as a network in the confluence state, we hypothesized that they may need more time to become arrhythmic. Therefore, the cardiomyocytes were incubated in $10 \mu \mathrm{mol} \mathrm{L}^{-1}$ ISO overnight. ISO was washed away before the electrophysiological recordings. This treatment induced a large variability in rhythmicity (Fig. 9a). We do not know the reason for this irregular firing, 
(a)

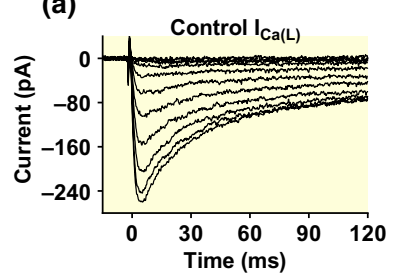

(e)

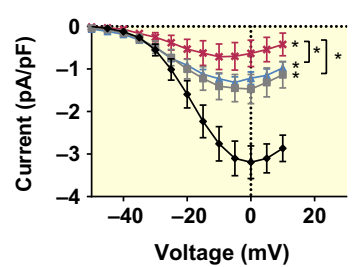

(b)

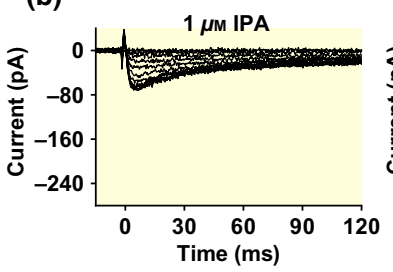

(f)

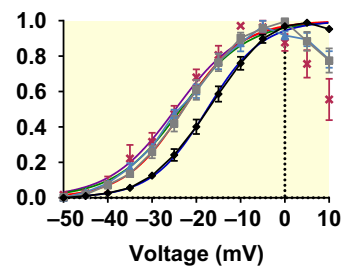

(c)

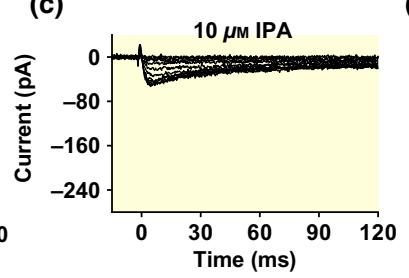

(g)

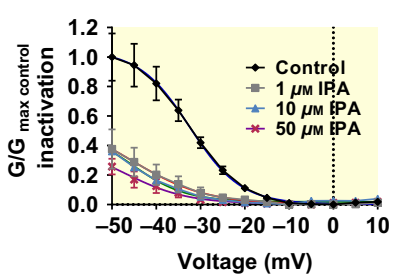

(d)

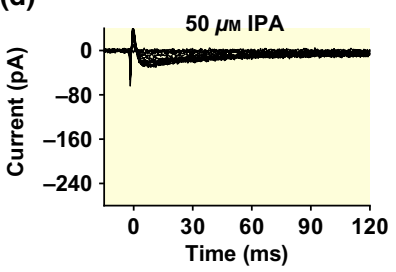

(h)

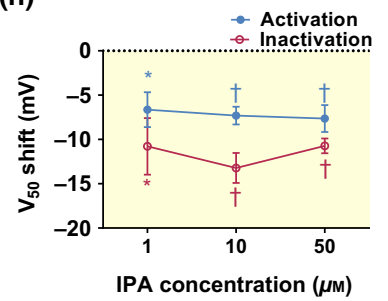

Figure 5 IPA effect on the L-type Ca current $\left(I_{\mathrm{Ca}(\mathrm{L})}\right)$. (a-d) Typical $\mathrm{I}_{\mathrm{Ca}(\mathrm{L})}$ traces before and after application of different IPA concentrations. Currents evoked by voltage steps between -50 and $+20 \mathrm{mV}$ in $5 \mathrm{mV}$ increments. Holding voltage was $-50 \mathrm{mV}$.

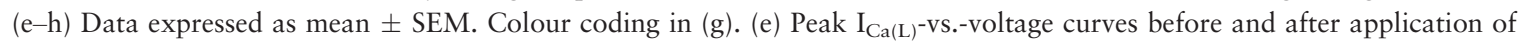
IPA. '*' indicates significant difference from control and between concentrations (bars) $(n=5 ; P<0.05)$. (f) Peak Ca(L)-conductance-vs.-voltage curves before and after application of IPA $(n=5)$. Data fitted to Eq. 2. (g) Steady-state inactivation curves were plotted as the peak currents at $-20 \mathrm{mV}$ versus voltage, following conditioning pulses of $1000 \mathrm{~ms}$ to voltages between $-50 \mathrm{mV}$ and +10 in $5 \mathrm{mV}$ increments, from a holding voltage of $-50 \mathrm{mV}(n=5)$. Data fitted to Eq. 2. (h) Summary of IPAinduced shifts from (f) and (g). Signs at the symbols indicate significant differences from $0\left(* P<0.05 ;{ }^{\dagger} P<0.01\right)$.

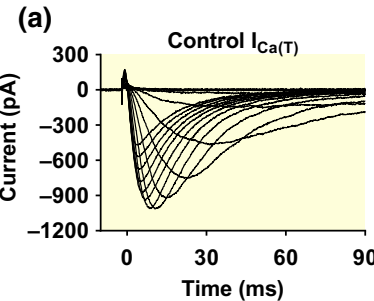

(e)

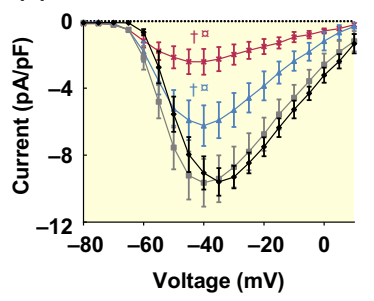

(b)

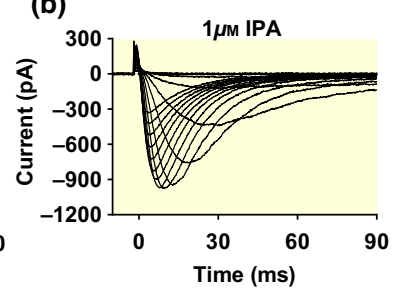

(f)

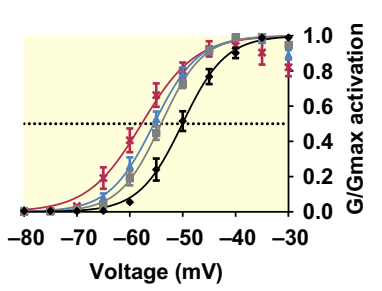

(c)

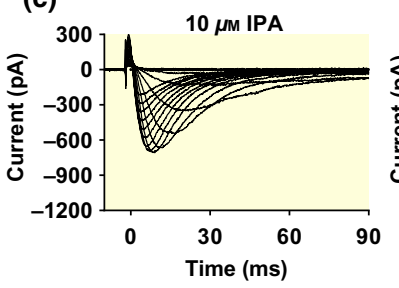

(g)

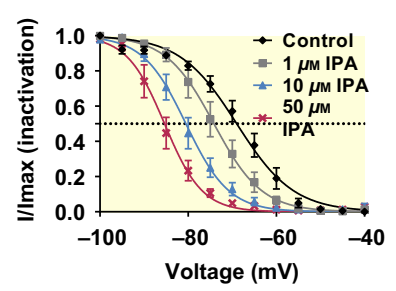

(d)
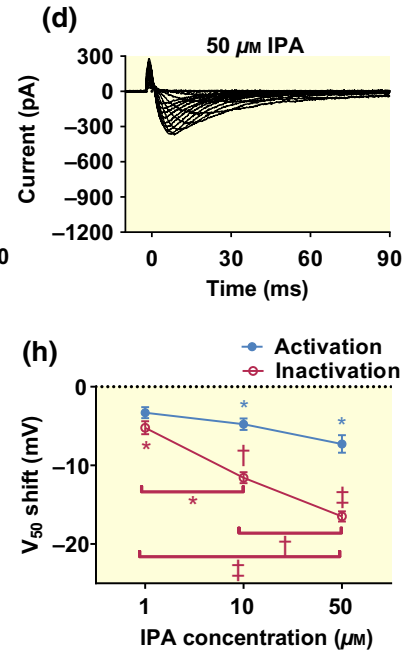

Figure 6 IPA effect on the T-type Ca current $\left(I_{\mathrm{Ca}(\mathrm{T})}\right)$. (a-d) Typical $\mathrm{I}_{\mathrm{Ca}(\mathrm{T})}$ traces before and after application of different IPA concentrations. Currents evoked by voltage steps between -80 and $-20 \mathrm{mV}$ in $5 \mathrm{mV}$ increments. Holding voltage was

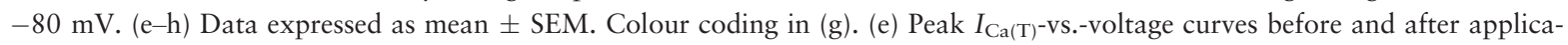
tion of IPA. '*' indicates significant difference from control $(n=4 ; P<0.05)$. (f) Peak Ca(T)-conductance-versus-voltage curves before and after application of IPA $(n=4)$. Data fitted to Eq. 2. (g) Steady-state inactivation curves were plotted as the peak currents at $-20 \mathrm{mV}$ versus voltage, following conditioning pulses of $1000 \mathrm{~ms}$ to voltages between -100 and $0 \mathrm{mV}$ in $5 \mathrm{mV}$ increments, from a holding voltage of $-80 \mathrm{mV}(n=4)$. Data fitted to Eq. 2. (h) Summary of IPA-induced shifts from (f) and (g). Signs at the symbols indicate significant differences from 0 , and $*$ at the line indicates significant difference between the groups $\left(* P<0.05 ;{ }^{\dagger} P<0.01 ;{ }^{*} P<0.001\right)$.

but we used it as a model of arrhythmia (e.g. AF). $10 \mu \mathrm{mol} \mathrm{L}{ }^{-1}$ IPA completely restored regular firing (Fig. 9b). The averaged data from several cells showed that $1 \mu \mathrm{mol} \mathrm{L}{ }^{-1}$ IPA had a clear effect on the irregular firing and almost completely restored regular firing (Fig. 9c). 
(a)

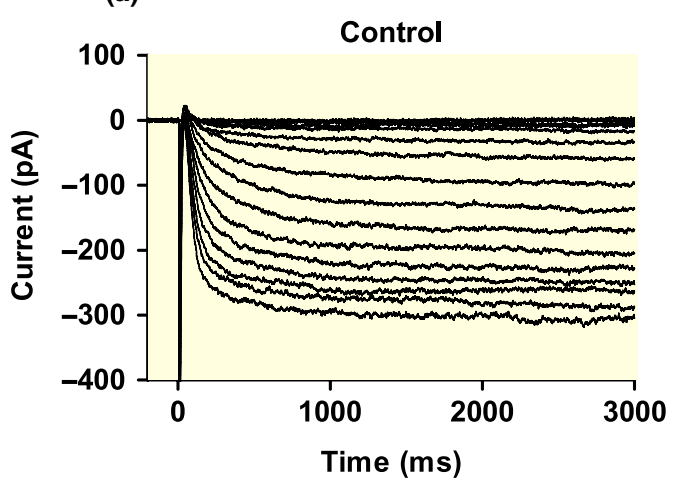

(c)

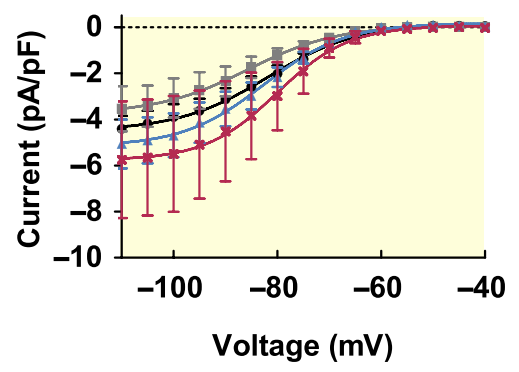

(b)

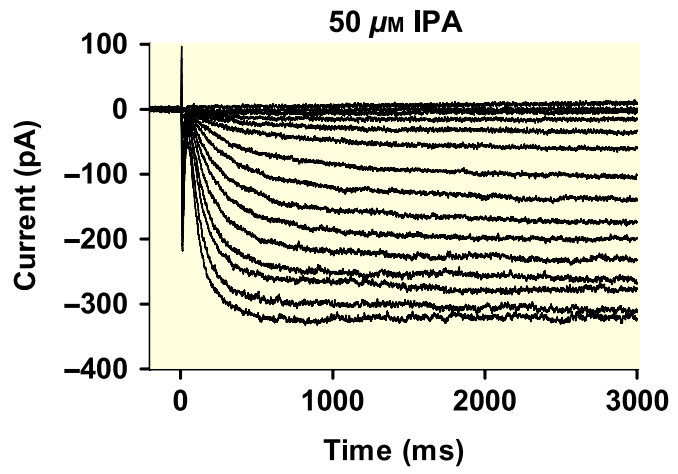

(e)
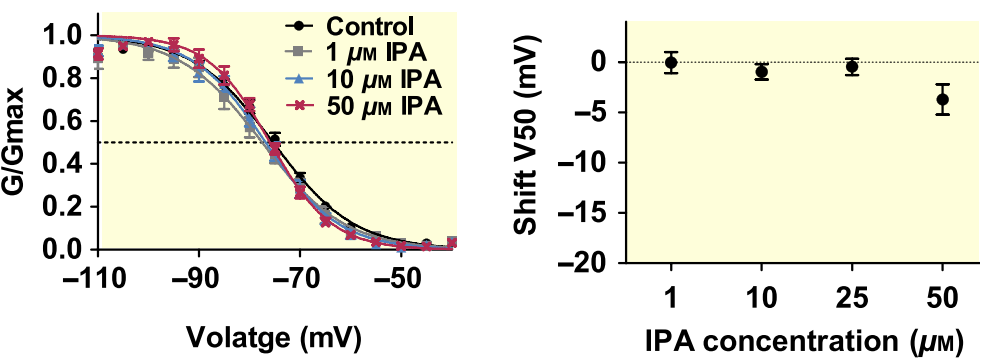

Figure 7 IPA effect on the hyperpolarization-activated non-selective cation current $\left(I_{\mathrm{f}}\right)$. (a, b) Typical $I_{\mathrm{f}}$ traces before and after application of $50 \mu \mathrm{mol} \mathrm{L}{ }^{-1}$ IPA. Currents evoked by voltage steps between -40 and $-115 \mathrm{mV}$ in $5 \mathrm{mV}$ increments. Holding voltage was $-40 \mathrm{mV}$. (c-e) Data expressed as mean \pm SEM. (c) Steady-state $I_{\mathrm{f}}$-vs.-voltage curves before and after application of IPA. Colour coding in (d). (d) $I_{\mathrm{f}}$-conductance-vs.-voltage curves before and after application of IPA $(n=6-4)$. Data fitted to Eq. 2. (e) Summary of IPA-induced shifts from (d). No significant effects.

(a)

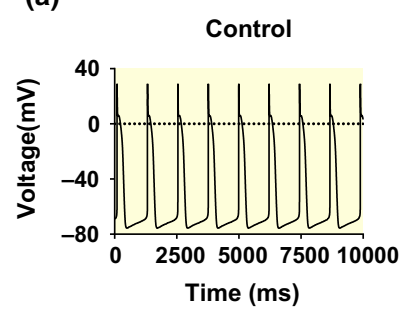

(e)

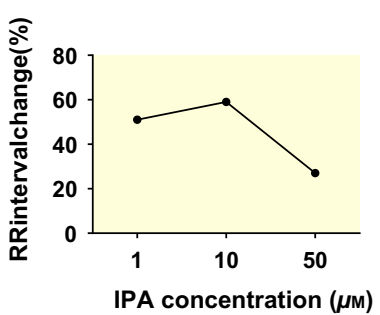

(b)

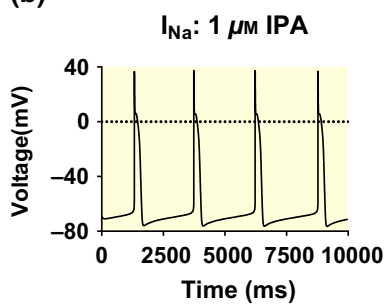

(f)

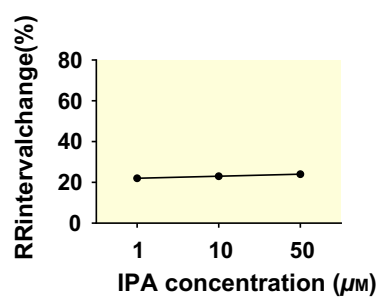

(c)

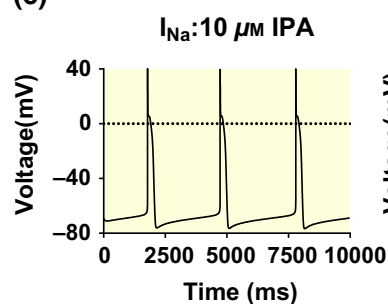

(g)

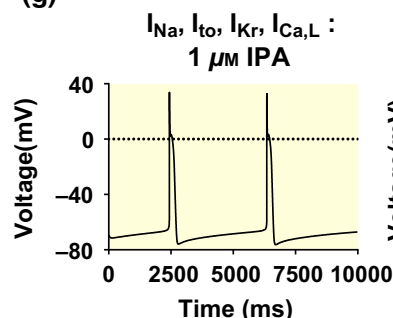

(d)

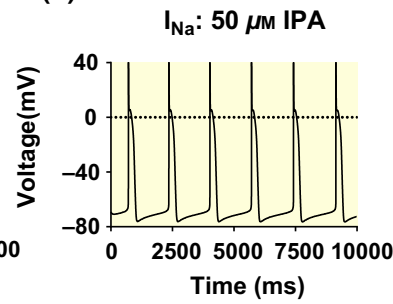

(h)

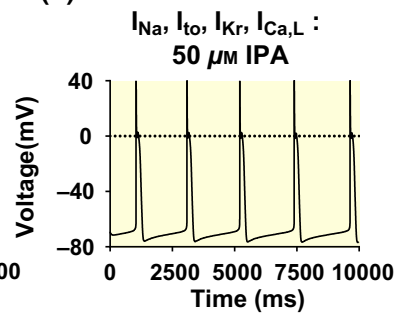

Figure 8 Simulation of action potentials according to experimental data, and IPA effects on induced arrhythmia in HL-1 cells. (a) Control action potentials. (b-d) Simulations in which $I_{\mathrm{Na}}$ gating has been altered according to experimental data at 1,10 and $50 \mu \mathrm{mol} \mathrm{L}^{-1}$. (e) Summary of change in RR interval (\%) compared to control when $I_{\mathrm{Na}}$ gating was altered. (f) Summary of change in RR interval (\%) compared to control when $I_{\mathrm{Ca}(\mathrm{L})}$ gating was altered. $(\mathrm{g}, \mathrm{h})$ Simulations in which all gating parameters $\left(I_{\mathrm{Na}}, I_{\mathrm{to}}, I_{\mathrm{Kr}}, I_{\mathrm{Ca}(\mathrm{L})}\right)$ were altered simultaneously for 1 and $50 \mu \mathrm{mol} \mathrm{L} \mathrm{L}^{-1}$. 
(a)

\section{Control (after incubation} in $10 \mu \mathrm{m}$ ISO)

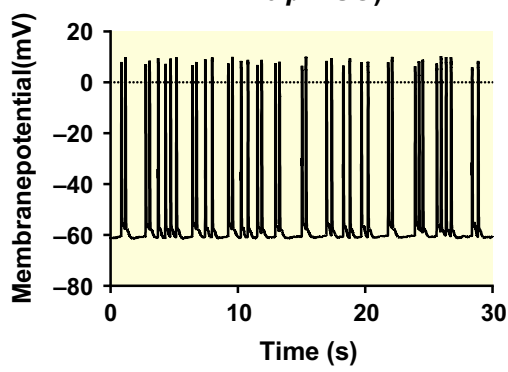

(b)

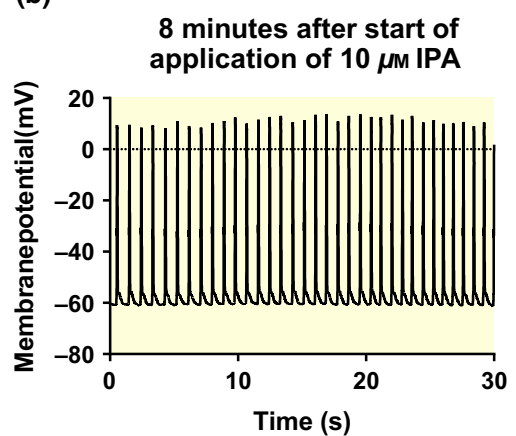

(c)

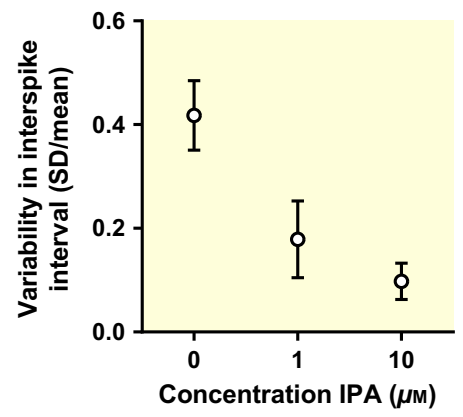

Figure 9 IPA restores arrhythmic firing. (a) Spontaneous action potentials after overnight incubation in $10 \mu \mathrm{M}$ ISO. (b) $10 \mu \mathrm{M}$ IPA restores regular rhythm. (c) Summary of data from four cells. Variability $=0$ means no irregularity.

\section{Discussion}

The present study has shown that the resin acid IPA affected several gating parameters of almost all studied ion channels in HL-1 atrial cells. An overarching finding, however, is that the steady-state inactivation curves of $I_{\mathrm{Na}}, I_{\mathrm{Ca}(\mathrm{L})}$, and $I_{\mathrm{Ca}(\mathrm{T})}$ were the most affected parameters, more than the activation, $G(V)$, curves of all channels. As a consequence, IPA also reduced the spontaneous action potential frequency as well as rescued the cells from a pharmacologically induced arrhythmic firing.

\section{IPA blocks $\mathrm{Na}$ and $\mathrm{Ca}$ channels while opening $\mathrm{K}$ channels - $a$ beneficial mix}

Four currents are excitatory when activated $I_{\mathrm{Na}}$, $I_{\mathrm{Ca}(\mathrm{L})}, I_{\mathrm{Ca}(\mathrm{T})}$ and $I_{\mathrm{f}}$. While $I_{\mathrm{f}}$ was not affected, the other three were affected in a similar fashion; both the $G(V)$ and the steady-state inactivation curves were shifted in the negative direction along the voltage axis, but the effect was roughly twice as large for inactivation than for activation. Two currents are inhibitory when activated $I_{\mathrm{Kr}}$ and $I_{\text {to }}$. For $I_{\mathrm{Kr}}$, the $G(V)$ curve was clearly shifted in the negative direction while leaving the steady-state inactivation unaffected. While the $G(V)$ curve for $I_{\text {to }}$ was not shifted along the voltage axis, the maximum conductance was increased. Surprisingly, despite no shift of the $G(V)$ curve, the steady-state inactivation curve was shifted in the negative directing along the voltage axis. However, at least in the lower concentration range, the shift was small. To summarize, the effect on four of the currents $\left(I_{\mathrm{Na}}\right.$, $I_{\mathrm{Ca}(\mathrm{L})}, I_{\mathrm{Ca}(\mathrm{T})}$ and $I_{\mathrm{Kr}}$ ) clearly suggests a reduction of excitability. The effect on the fifth current $\left(I_{\text {to }}\right)$ is ambiguous, with an increased current in combination with a left-shifted steady-state inactivation curve. Altogether, the data from the ion currents suggest that IPA should reduce excitability.

\section{Comparisons between PUFAs and IPA - some ideas for} the molecular mechanisms

Even though we have not detailed the molecular mechanism of IPA on the different ion channels explored in the present investigation, all data fit with the hypothesis that IPA integrates into the lipid membrane near the ion channels' voltage sensors and, from this position, electrostatically affects the channel's voltage-sensing mechanism. ${ }^{16,25}$ A negative charge will activate the channel by attracting the voltage sensors positively charged residues, while a positive charge will have the opposite effect. The inactivation of $\mathrm{Na}$ channels has been linked to the movement of S4 of domain IV, ${ }^{30-32}$ and thus, a compound supporting the outward movement of S4IV should theoretically also promote inactivation. The effects quantitatively differ between different ion channels and between activation and inactivation, which is not unexpected because of different charge profiles at the extracellular end of different S4s. ${ }^{16}$

Polyunsaturated fatty acids act similarly to IPA and other resin acids. ${ }^{16,25}$ Because the molecular mechanism of PUFAs on voltage-gated ion channels has been studied in detail, ${ }^{12-16,33}$ they can probably suggest the molecular mechanism for IPA. The PUFA docosahexaenoic acid (DHA) and eicosapentaenoic acid (EPA) have strong inhibitory effects on the action potential frequency in cardiomyocytes, ${ }^{34-37}$ and they shorten the action potential while having negligible effects on the resting membrane potential and the action potential amplitude. ${ }^{36-38}$ These findings are similar to our findings of IPA. Furthermore, DHA, EPA, linoleic acid and arachidonic acid reduce $I_{\mathrm{Na}}, I_{\mathrm{Ca}(\mathrm{L})}$ and $I_{\mathrm{Ca}(\mathrm{T})}$ and shift the steady-state inactivation curves in the negative direction along the voltage axis while leaving the $G(V)$ curves essentially unaffected. ${ }^{38-42}$ In addition, there are also indications of specificity for the effects; DHA has a larger inhibitory effect on $I_{\mathrm{Na}}$, while EPA 
has larger effects on $I_{\mathrm{Ca} .}{ }^{41,43}$ DHA inhibits $I_{\text {to }}$ in cardiomyocytes by shifting the steady-state inactivation curve in the negative direction along the voltage axis while leaving the $G(V)$ curve unaffected, ${ }^{44,45}$ similar to our results for IPA on $I_{\text {to }}$. DHA and arachidonic acid shift the conductance curve of $I_{\mathrm{Kr}}$ to more negative voltages, ${ }^{46}$ similar to our effects with IPA. In summary, the striking similarities in effects between IPA and PUFAs suggest they act via a similar mechanism.

Fatty acids are also known to reduce ion currents through connexin-based ion channels, ${ }^{47}$ which are widely distributed in the heart. The ion channel-modulating kinship between resin acids and PUFAs suggests the possibility that resin acids can also affect connexin-based ion channels. However, PUFAs are known to have multiple effects and binding sites on voltage-gated ion channels, ${ }^{17}$ of which just a few are shared with resin acids. In addition, we are not aware of any reported effects of resin acids on connexinbased ion channels.

\section{Promiscuous effects on several ion channels pave the way to potential clinical usefulness?}

We recently proposed that simultaneous modulation of different ion channels can be a rational therapeutic strategy for cardiac arrhythmia and epilepsy. ${ }^{12,48}$ The present study supports this hypothesis, even though it should be emphasized that the HL-1 cell findings in the present investigation are not directly applicable to AF of an intact human heart. IPA at $1 \mu \mathrm{mol} \mathrm{L}{ }^{-1}$ had profound effects on the cardiomyocytes by decreasing the action potential frequency and by reducing $\mathrm{APD}_{50}$ in a similar fashion as PUFAs. ${ }^{36}$

Atrial fibrillation is associated with several cellular alterations: (i) $\mathrm{Ca}^{2+}$ overload has an important role in the initiation and maintenance of $\mathrm{AF}^{49,50}$; a reduced action potential frequency and a shorter action potential can limit the $\mathrm{Ca}^{2+}$ influx and protect the cardiomyocytes from $\mathrm{Ca}^{2+}$ overload. (ii) The late (i.e. steady-state) $I_{\mathrm{Na}}$ is increased in atrial cardiomyocytes derived from patients with chronic AF; an inhibition of the current has been suggested as a new treatment option for AF. ${ }^{51}$ (iii) $I_{\text {to }}$ is reduced by $70 \%$ during the remodelling process followed by chronic $\mathrm{AF}^{52}$; it is well established that the remodelling process stabilizes AF in the atrium via structural changes in atrial cardiomyocytes. ${ }^{53}$ The present investigation suggests that IPA has beneficial effects on all three AF-associated cellular alterations: (i) IPA is expected to reduce the $\mathrm{Ca}^{2+}$ influx by promoting inactivation of both L- and T-type channels, by reducing the frequency and by reducing $\mathrm{APD}_{30}$. PUFAs, but not IPA, decreased $\mathrm{APD}_{90}{ }^{36,37}$; a reduced $\mathrm{APD}_{90}$ abbreviates the refractory period and can increase the risk of delayed after depolarization (DAD) and re-entry phenomena which are two key mechanisms for AF initiation. ${ }^{53}$ This difference makes IPA a better candidate for AF prevention than PUFAs. (ii) DHA and EPA decrease the late $I_{\mathrm{Na}}$ and protect cardiomyocytes against arrhythmia during ischaemia. ${ }^{40}$ In the present investigation, IPA also decreased the late $I_{\mathrm{Na}}$ and can thus be antiarrhythmic in cardiomyocytes. ${ }^{40,51}$ (iii) IPA increased $\mathrm{I}_{\text {to }}$, which can rescue the heart from AF. In conclusion, IPA reduces action potential frequency and $\mathrm{Ca}$ influx without affecting refractory period. It also promotes $I_{\mathrm{Na}}$ inactivation and increases $I_{\text {to }}$ in atrial cardiomyocytes. Even though findings of the HL-1 cell line in the present investigation are not directly applicable to AF of an intact human heart, all of the beneficial effects described above make IPA worth exploring further as a drug candidate for AF treatment and prevention.

\section{Concluding remarks}

The present investigation has (i) demonstrated that a new type of small-molecule compound, IPA, affects cardiac rhythmicity and can potentially be developed into a compound against AF. IPA is also (ii) the first drug-like small-molecule compound acting on voltagegated ion channels in cardiomyocytes via an electrostatic mechanism. It shows that (iii) the largest effects are on the inactivation mechanism of $\mathrm{Na}$, and $\mathrm{L}-$ and T-type Ca channels. This investigation also suggests that (iv) promiscuous multi-targeting effects on several ion channels might be a beneficial strategy to treat cardiac arrhythmia.

\section{Material and methods}

The study conforms with that of Persson. ${ }^{54}$

\section{Chemicals}

All chemicals were purchased from Sigma-Aldrich (Stockholm, Sweden) except for IPA (Alomone laboratories, Jerusalem, Israel). IPA was diluted in ethanol in a $100 \mathrm{mmol} \mathrm{L}^{-1}$ stock solution and isoproterenol (ISO) in deionized water in a $10 \mathrm{mmol} \mathrm{L}^{-1}$ stock solution. The stock solutions were stored at $-20^{\circ} \mathrm{C}$ for further use.

\section{Cell culture}

The cell culture was carried out according to a previous study. ${ }^{26}$ In brief, HL-1 cells were grown on gelatin-fibronectin-coated T75 flasks. They were maintained in Claycomb medium that was supplemented 
with $10 \%$ foetal bovine serum, $2 \mathrm{mmol} \mathrm{L}^{-1}$ L-glutamine, $0.1 \mathrm{mmol} \mathrm{L}^{-1}$ noradrenaline and $100 \mathrm{U} \mathrm{mL}^{-1}$, $100 \mu \mathrm{g} \mathrm{mL}^{-1}$ penicillin-streptomycin. Enzymatic dissociation with $0.05 \%$ trypsin-EDTA was carried out after full confluence. Isolated cells were plated on gelatin-fibronectin-coated plastic coverslips and used for recording.

\section{Electrophysiology}

Whole-cell current-clamp recordings were carried out on confluent cells at $35 \pm 1^{\circ} \mathrm{C}$, using an Axopatch 200B amplifier (Molecular Devices, Sunnyvale, CA, USA). Patch pipettes were fabricated from borosilicate capillary glass on a vertical pipette puller and had resistances of 3-5 M . Data were stored on a computer through the Digidata 1440A interface (Molecular Devices) and were analysed with pCLAMP software (version 10.1, Molecular Devices). The bath solution contained the following (in $\mathrm{mmol} \mathrm{L}^{-1}$ ): $140 \mathrm{NaCl}, 5.4 \mathrm{KCl}, 1 \mathrm{MgCl}_{2}, 1.8 \mathrm{CaCl}_{2}, 10 \mathrm{HEPES}$ and 10 glucose ( $\mathrm{pH}$ adjusted to 7.4 with $\mathrm{NaOH}$ ). The micropipettes were filled with a solution containing (in $\mathrm{mmol} \mathrm{L}^{-1}$ ): $130 \mathrm{~K}$-gluconate, $9 \mathrm{KCl}, 8 \mathrm{NaCl}, 1$ $\mathrm{MgCl}_{2}, 10$ EGTA, 10 HEPES and $3 \mathrm{Na}_{2} \mathrm{ATP}$ (pH adjusted to 7.3 with $\mathrm{KOH}$ ). APs were not corrected for junction potential.

Voltage-clamp recordings were carried out on single cells at room temperature. The pipettes had a tip resistance of 1-3 M . Before formation of the membrane-pipette seal, tip potentials were zeroed in bath solution. Junction potentials were calculated and applied in protocols. Series resistances and membrane capacitance were compensated for following whole-cell access before recordings. Current density $\left(\mathrm{pA} \mathrm{pF}^{-1}\right)$ was calculated by dividing the current amplitude by the membrane capacitance. To assess voltage dependence of activation, conductance $(G)$ was calculated using the following equation:

$G(V)=I(V)\left(V-V_{\text {rev }}\right)^{-1}$,

where $V$ is the absolute membrane potential, $I$ the peak or steady-state current and $V_{\text {rev }}$ the reversal potential. To evaluate the voltage dependence of the $G(V)$ curves or the steady-state inactivation curves (peak current amplitudes plotted versus the pre-pulse membrane potential), data points were normalized to the maximum current and fitted to a Boltzmann curve:

$G(V) G_{\max }^{-1}=\left(1+\exp \left(\left(V-V_{50}\right) \mathrm{s}^{-1}\right)\right)^{-1}$,

where $V_{50}$ is the midpoint and $s$ the slope factor.

To measure $I_{\mathrm{Na}}$, the bath solution contained (in mmol L ${ }^{-1}$ ): $15 \mathrm{NaCl}$ (low concentration to reduce series resistance artefacts), 124 choline chloride, 1
$\mathrm{MgCl}_{2}, 1.8 \mathrm{CaCl}_{2}, 10$ HEPES and 10 glucose $(\mathrm{pH}$ adjusted to 7.4 with $\mathrm{CsOH}$ ). 5 TEA-Cl, $1 \mathrm{CoCl}_{2}, 2$ 4-aminopyridine and $0.5 \mathrm{BaCl}_{2}$ were added to the bath solution to block TEA-sensitive $\mathrm{K}$ currents, $I_{\mathrm{Ca}}$, $I_{\text {to }}$ and $I_{\mathrm{K} 1}$ respectively. The pipette solution contained (in $\mathrm{mmol} \mathrm{L}^{-1}$ ): $125 \mathrm{CsF}, 15 \mathrm{NaCl}, 1 \mathrm{MgCl}_{2}, 10$ EGTA, 10 HEPES and $3 \mathrm{Mg}$-ATP. To measure $I_{\mathrm{Kr}}$, the bath and pipette solutions were the same as the solutions in the current-clamp recordings except that $\mathrm{Na}_{2}$ ATP was replaced with $\mathrm{Mg}$-ATP. To block $I_{\mathrm{Ca}(\mathrm{L})}$, $10 \mu \mathrm{mol} \mathrm{L}^{-1}$ nifedipine was added to the bath solution. To measure $I_{\text {to }}$, the bath solution contained (in mmol L ${ }^{-1}$ ): 140 choline chloride, $5.4 \mathrm{KCl}, 1 \mathrm{MgCl}_{2}$, $1.8 \mathrm{CaCl}_{2}, 10$ HEPES and 10 glucose $(\mathrm{pH}$ adjusted to 7.4 with $\mathrm{KOH}$ ). The pipette solution contained (in mmol L ${ }^{-1}$ ): $130 \mathrm{~K}$-gluconate, $9 \mathrm{KCl}, 1 \mathrm{MgCl}_{2}, 10$ EGTA, 10 HEPES and $3 \mathrm{Mg}$-ATP (pH adjusted to 7.3 with $\mathrm{KOH}$ ). $1 \mathrm{CoCl}_{2}$ and $0.001 \mathrm{E} 4030$ were added to the bath solution to block $I_{\mathrm{Ca}}$ and $I_{\mathrm{Kr}}$ respectively. To measure $I_{\mathrm{Ca}(\mathrm{T})}$ and $I_{\mathrm{Ca}(\mathrm{L})}$, the bath solution contained (in $\mathrm{mmol} \mathrm{L}^{-1}$ ): 140 choline chloride, $1 \mathrm{MgCl}_{2}, 5$ $\mathrm{CaCL}_{2}, 10$ glucose and 10 HEPES. The pipette solution contained (in mmol L ${ }^{-1}$ ): $110 \mathrm{CsCl}, 20 \mathrm{TEA}-\mathrm{Cl}$, 10 EGTA, 10 HEPES and $3 \mathrm{Mg}$-ATP. To measure $I_{\mathrm{Ca}}$ (T), $10 \mu \mathrm{mol} \mathrm{L}{ }^{-1}$ nifedipine was added to the bath solution to inhibit $I_{\mathrm{Ca}(\mathrm{L})}$. To measure $I_{\mathrm{Ca}(\mathrm{L})}$, the membrane potential was held at $-50 \mathrm{mV}$ to inhibit $I_{\mathrm{Ca}(\mathrm{T})}$. To measure $I_{\mathrm{f}}$, the bath solution contained (in mmol L ${ }^{-1}$ ): $120 \mathrm{NaCl}, 1.8 \mathrm{CaCl}_{2}, 1 \mathrm{MgCl}_{2}, 10$ glucose, 5 HEPES, $2 \mathrm{NiCl}_{2}, 2 \mathrm{BaCl}_{2}$ and 0.5 4-aminopyridine. $30 \mathrm{KCl}$ was used to amplify $I_{\mathrm{f}}$. The pipette solution contained (in $\mathrm{mmol} \mathrm{L}^{-1}$ ): $120 \mathrm{~K}$-gluconate, $10 \mathrm{HEPES}, 11 \mathrm{EGTA}, 5 \mathrm{CaCl}_{2}, 2 \mathrm{MgCl}_{2}$ and 10 TEA-Cl. $5 \mathrm{Na}_{2}$-ATP and $0.4 \mathrm{Na}_{2}$-ATP were added the same day as usage.

To induce arrhythmia, we added $10 \mu \mathrm{mol} \mathrm{L}^{-1}$ ISO to $\mathrm{Hl}-1$ cell medium and incubated them overnight. In each preparation, we kept some wells intact to make sure that the cardiomyocytes were healthy before adding ISO.

\section{Computer simulations}

Action potentials were simulated using the Stewart model of Purkinje fibre cells. ${ }^{55}$ The model was implemented in MATLAB R2014a (Mathworks, Natick, MA, USA) and solved using the variable order stiff differential equation solver (ode15s). ${ }^{56}$

\section{Statistical analysis}

pCLAMP 10 and GraphPad Prism 6 programs were used to analyse data. Action potential parameters including the resting membrane potential, the action potential amplitude, the maximum rising slope, the 
maximum decay slope and the action potential widths measured at 30, 50 and 90\% levels (measured from the peak; $\mathrm{APD}_{30}, \mathrm{APD}_{50}$, and $\mathrm{APD}_{90}$ ) - were measured by pCLAMP software. Results were expressed as means \pm SEM, and differences between means were computed by Student's $t$-tests and ANOVA.

\section{Conflict of interest}

The authors do not declare any conflict of interests.

The HL-1 cardiac cell line was a generous gift from William C. Claycomb (Louisiana State University). We thank Peter Larsson, University of Miami and Sara Liin, Linköping University, for critical comments on the manuscript and Alexis Reisch for linguistic advice. This work was supported by grants from the Swedish Research Council, the Swedish HeartLung Foundation, the Swedish Brain Foundation and ALF.

\section{References}

1. Wolf PA, Abbott RD, Kannel WB: Atrial fibrillation as an independent risk factor for stroke: the Framingham Study. Stroke 22: 983-988, 1991.

2. Schnabel RB, Yin X, Gona P, Larson MG, Beiser AS, McManus DD, Newton-Cheh C, Lubitz SA, Magnani JW, Ellinor PT, Seshadri S, Wolf PA, Vasan RS, Benjamin EJ, Levy D: 50 year trends in atrial fibrillation prevalence, incidence, risk factors, and mortality in the Framingham Heart Study: a cohort study. Lancet 386: 154-162, 2015

3. Burashnikov A, Antzelevitch C: New developments in atrial antiarrhythmic drug therapy. Nat Rev Cardiol 7: 139-148, 2010.

4. Darbar D, Roden DM: Genetic mechanisms of atrial fibrillation: impact on response to treatment. Nat Rev Cardiol 10: 317-329, 2013.

5. Buxton AE, Lee KL, Fisher JD, Josephson ME, Prystowsky EN, Hafley G: A randomized study of the prevention of sudden death in patients with coronary artery disease. Multicenter unsustained tachycardia trial investigators. N Engl J Med 341: 1882-1890, 1999.

6. Echt DS, Liebson PR, Brent Mitchell L, Peters RW, Obias-Manno D, Barker AH, Arensberg D, Baker A, Friedman L, Leon Greene H, Huther ML, Richardson DW, and the CAST Investigators: Mortality and morbidity in patients receiving encainide, flecainide, or placebo. The cardiac arrhythmia suppression trial. $\mathrm{N} \mathrm{Engl} \mathrm{J} \mathrm{Med}$ 324: 781-788, 1991.

7. Waldo AL, Camm AJ, deRuyter H, Friedman PL, MacNeil DJ, Pauls JF, Pitt B, Pratt CM, Schwartz PJ, Veltri EP: Effect of d-sotalol on mortality in patients with left ventricular dysfunction after recent and remote myocardial infarction. The SWORD Investigators. Survival With Oral d-Sotalol. Lancet 348: 7-12, 1996.

8. Bardy GH, Lee KL, Mark DB, Poole JE, Packer DL, Boineau R, Domanski M, Troutman C, Anderson J, Johnson G, McNulty SE, Clapp-Channing N, Davidson-Ray LD,
Fraulo ES, Fishbein DP, Luceri RM, Ip JH: Sudden cardiac death in heart failure trial, I: amiodarone or an implantable cardioverter-defibrillator for congestive heart failure. N Engl J Med 352: 225-237, 2005.

9. Jahangiri A, Leifert WR, Patten GS, McMurchie EJ: Termination of asynchronous contractile activity in rat atrial myocytes by $\mathrm{n}-3$ polyunsaturated fatty acids. Mol Cell Biochem 206: 33-41, 2000.

10. Mozaffarian D, Psaty BM, Rimm EB, Lemaitre RN, Burke GL, Lyles MF, Lefkowitz D, Siscovick DS: Fish intake and risk of incident atrial fibrillation. Circulation 110: 368-373, 2004.

11. Metcalf RG, Skuladottir GV, Indridason OS, Sullivan TR, Bjorgvinsdottir L, Sanders P, Arnar DO, Gibson RA, Heidarsdottir R, Cleland LG, Palsson R, Farquharson AL, Young GD, James MJ: U-shaped relationship between tissue docosahexaenoic acid and atrial fibrillation following cardiac surgery. Eur J Clin Nutr 68: 114-118, 2014.

12. Borjesson SI, Hammarstrom S, Elinder F: Lipoelectric modification of ion channel voltage gating by polyunsaturated fatty acids. Biophys J 95: 2242-2253, 2008.

13. Borjesson SI, Parkkari T, Hammarstrom S, Elinder F: Electrostatic tuning of cellular excitability. Biophys $J$ 98: 396-403, 2010.

14. Borjesson SI, Elinder F: An electrostatic potassium channel opener targeting the final voltage sensor transition. $J$ Gen Physiol 137: 563-577, 2011.

15. Liin, SI, Silvera Ejneby, M, Barro-Soria, R, Skarsfeldt, MA, Larsson, JE, Starck Harlin, F, Parkkari, T, Bentzen, BH, Schmitt, N, Larsson, HP, Elinder, F: Polyunsaturated fatty acid analogs act antiarrhythmically on the cardiac IKs channel. Proc Natl Acad Sci USA, 112: 5714-5719, 2015.

16. Ottosson NE, Liin SI, Elinder F: Drug-induced ion channel opening tuned by the voltage sensor charge profile. $J$ Gen Physiol 143: 173-182, 2014.

17. Elinder F, Liin SI: Actions and mechanisms of polyunsaturated fatty acids on voltage-gated ion channels. Front Physiol 8: 43, 2017.

18. Norin T, Winell B: Diterpenoids of cones from two Cedrus species. Phytochemistry 10: 2818-2821, 1971.

19. Beath, OA: On abietic acid and related resin acids from oleoresin of American Conifers. University of WisconsinMadison, https://archive.org/details/onabieticacidan00bea tgoog, 1912.

20. Imaizumi Y, Sakamoto K, Yamada A, Hotta A, Ohya S, Muraki K, Uchiyama M, Ohwada T: Molecular basis of pimarane compounds as novel activators of large-conductance $\mathrm{Ca}(2+)$-activated $\mathrm{K}(+)$ channel alpha-subunit. Mol Pharmacol 62: 836-846, 2002.

21. Kobayashi K, Nishizawa Y, Sawada K, Ogura H, Miyabe $\mathrm{M}$ : $\mathrm{K}(+)$-channel openers suppress epileptiform activities induced by 4-aminopyridine in cultured rat hippocampal neurons. J Pharmacol Sci 108: 517-528, 2008.

22. Wu, C, V Gopal, K, Lukas, TJ, Gross, GW, Moore, EJ: Pharmacodynamics of potassium channel openers in cultured neuronal networks. Eur J Pharmacol, 732: 68-75, 2014.

23. Jacobson DA, Mendez F, Thompson M, Torres J, Cochet O, Philipson LH: Calcium-activated and voltage- 
gated potassium channels of the pancreatic islet impart distinct and complementary roles during secretagogue induced electrical responses. J Physiol 588: 3525-3537, 2010.

24. Harrell MD, Harbi S, Hoffman JF, Zavadil J, Coetzee WA: Large-scale analysis of ion channel gene expression in the mouse heart during perinatal development. Physiol Genomics 28: 273-283, 2007.

25. Ottosson NE, Wu X, Nolting A, Karlsson U, Lund PE, Ruda K, Svensson S, Konradsson P, Elinder F: Resin-acid derivatives as potent electrostatic openers of voltagegated $\mathrm{K}$ channels and suppressors of neuronal excitability. Sci Rep 5: 13278, 2015.

26. Claycomb WC, Lanson NA Jr, Stallworth BS, Egeland DB, Delcarpio JB, Bahinski A, Izzo NJ Jr: HL-1 cells: a cardiac muscle cell line that contracts and retains phenotypic characteristics of the adult cardiomyocyte. Proc Natl Acad Sci USA 95: 2979-2984, 1998.

27. Yang Z, Shen W, Rottman JN, Wikswo JP, Murray KT: Rapid stimulation causes electrical remodeling in cultured atrial myocytes. J Mol Cell Cardiol 38: 299-308, 2005.

28. Sartiani L, Bochet P, Cerbai E, Mugelli A, Fischmeister R: Functional expression of the hyperpolarization-activated, non-selective cation current $\mathrm{I}(\mathrm{f})$ in immortalized HL-1 cardiomyocytes. J Physiol 545: 81-92, 2002.

29. Xia M, Salata JJ, Figueroa DJ, Lawlor AM, Liang HA, Liu Y, Connolly TM: Functional expression of L- and Ttype $\mathrm{Ca}^{2+}$ channels in murine HL-1 cells. J Mol Cell Cardiol 36: 111-119, 2004.

30. Chen LQ, Santarelli V, Horn R, Kallen RG: A unique role for the $S 4$ segment of domain 4 in the inactivation of sodium channels. J Gen Physiol 108: 549-556, 1996.

31. Keynes RD, Elinder F: Modelling the activation, opening, inactivation and reopening of the voltage-gated sodium channel. Proc Biol Sci 265: 263-270, 1998.

32. Cha A, Ruben PC, George AL Jr, Fujimoto E, Bezanilla F: Voltage sensors in domains III and IV, but not I and II, are immobilized by $\mathrm{Na}^{+}$channel fast inactivation. Neuron 22: 73-87, 1999.

33. Liin SI, Karlsson U, Bentzen BH, Schmitt N, Elinder F: Polyunsaturated fatty acids are potent openers of human M-channels expressed in Xenopus laevis oocytes. Acta Physiol (Oxf) 218: 28-37, 2016.

34. Negretti N, Perez MR, Walker D, O’Neill SC: Inhibition of sarcoplasmic reticulum function by polyunsaturated fatty acids in intact, isolated myocytes from rat ventricular muscle. J Physiol 523(Pt. 2): 367-375, 2000.

35. Kang JX, Leaf A: Prevention and termination of betaadrenergic agonist-induced arrhythmias by free polyunsaturated fatty acids in neonatal rat cardiac myocytes. Biochem Biophys Res Comm 208: 629-636, 1995.

36. Den Ruijter HM, Verkerk AO, Coronel R: Incorporated fish oil fatty acids prevent action potential shortening induced by circulating fish oil fatty acids. Front Physiol 1: 149, 2010.

37. Verkerk AO, van Ginneken AC, Berecki G, den Ruijter HM, Schumacher CA, Veldkamp MW, Baartscheer A, Casini S, Opthof T, Hovenier R, Fiolet JW, Zock PL,
Coronel R: Incorporated sarcolemmal fish oil fatty acids shorten pig ventricular action potentials. Cardiovasc Res 70: 509-520, 2006.

38. Kang JX, Xiao YF, Leaf A: Free, long-chain, polyunsaturated fatty acids reduce membrane electrical excitability in neonatal rat cardiac myocytes. Proc Natl Acad Sci USA 92: 3997-4001, 1995.

39. Li GR, Sun HY, Zhang XH, Cheng LC, Chiu SW, Tse HF, Lau CP: Omega-3 polyunsaturated fatty acids inhibit transient outward and ultra-rapid delayed rectifier $\mathrm{K}^{+}$currents and $\mathrm{Na}^{+}$current in human atrial myocytes. Cardiovasc Res 81: 286-293, 2009.

40. Pignier C, Revenaz C, Rauly-Lestienne I, Cussac D, Delhon A, Gardette J, Le Grand B: Direct protective effects of poly-unsaturated fatty acids, DHA and EPA, against activation of cardiac late sodium current: a mechanism for ischemia selectivity. Basic Res Cardiol 102: 553-564, 2007.

41. Xiao YF, Gomez AM, Morgan JP, Lederer WJ, Leaf A: Suppression of voltage-gated L-type $\mathrm{Ca}^{2+}$ currents by polyunsaturated fatty acids in adult and neonatal rat ventricular myocytes. Proc Natl Acad Sci USA 94: 4182-4187, 1997.

42. Danthi SJ, Enyeart JA, Enyeart JJ: Modulation of native T-type calcium channels by omega-3 fatty acids. Biochem Biophys Res Comm 327: 485-493, 2005.

43. Vreugdenhil M, Bruehl C, Voskuyl RA, Kang JX, Leaf A, Wadman WJ: Polyunsaturated fatty acids modulate sodium and calcium currents in CA1 neurons. Proc Natl Acad Sci USA 93: 12559-12563, 1996.

44. Singleton CB, Valenzuela SM, Walker BD, Tie H, Wyse KR, Bursill JA, Qiu MR, Breit SN, Campbell TJ: Blockade by N-3 polyunsaturated fatty acid of the Kv4.3 current stably expressed in Chinese hamster ovary cells. $\mathrm{Br}$ J Pharmacol 127: 941-948, 1999.

45. Lai LH, Dong PS, Li ZZ, Li ZJ, Wang RX, Jiang WP: Effects of docosahexaenoic acid on sodium channel current and transient outward potassium channel current in rat ventricular myocytes. Zhonghua Xin Xue Guan Bing Za Zhi 39: 451-456, 2011.

46. Guizy M, Arias C, David M, Gonzalez T, Valenzuela C: \{Omega\}-3 and \{omega\}-6 polyunsaturated fatty acids block HERG channels. Am J Physiol Cell Physiol 289: C1251-C1260, 2005.

47. Puebla C, Retamal MA, Acuña R, Sáez JC: Regulation of connexin-based channels by fatty acids. Front Physiol 8: 11, 2017.

48. Tigerholm J, Borjesson SI, Lundberg L, Elinder F, Fransen E: Dampening of hyperexcitability in CA1 pyramidal neurons by polyunsaturated fatty acids acting on voltage-gated ion channels. PLoS One 7: e44388, 2012.

49. Van Wagoner DR, Pond AL, Lamorgese M, Rossie SS, McCarthy PM, Nerbonne JM: Atrial L-type $\mathrm{Ca}^{2+}$ currents and human atrial fibrillation. Circ Res 85: 428-436, 1999.

50. Niwano, S, Fukaya, H, Sasaki, T, Hatakeyama, Y, Fujiki, A, Izumi, T: Effect of oral L-type calcium channel blocker on repetitive paroxysmal atrial fibrillation: spectral analysis of fibrillation waves in the Holter monitoring. Europace, 9: 1209-1215, 2007. 
51. Sossalla S, Kallmeyer B, Wagner S, Mazur M, Maurer U, Toischer K, Schmitto JD, Seipelt R, Schondube FA, Hasenfuss G, Belardinelli L, Maier LS: Altered $\mathrm{Na}(+)$ currents in atrial fibrillation effects of ranolazine on arrhythmias and contractility in human atrial myocardium. J Am Coll Cardiol 55: 2330-2342, 2010.

52. Bosch RF, Zeng X, Grammer JB, Popovic K, Mewis C, Kuhlkamp V: Ionic mechanisms of electrical remodeling in human atrial fibrillation. Cardiovasc Res 44: 121131, 1999.

53. Heijman J, Voigt N, Nattel S, Dobrev D: Cellular and molecular electrophysiology of atrial fibrillation initiation, maintenance, and progression. Circ Res 114: 14831499, 2014.

54. Persson P: Good publication practice in physiology 2013: revised author guidelines for Acta Physiologica. Acta Physiol 209: 250-253, 2013.
55. Stewart P, Aslanidi OV, Noble D, Noble PJ, Boyett MR, Zhang H: Mathematical models of the electrical action potential of Purkinje fibre cells. Philos Trans A Math Phys Eng Sci 367: 2225-2255, 2009.

56. Shampine LF, Reichelt MW: The matlab ode suite. SIAM J Sci Comput 18: 1-22, 1997.

\section{Supporting Information}

Additional Supporting Information may be found online in the supporting information tab for this article:

Figure S1. Effect of acute application of ISO $10 \mu \mathrm{M}$ on cardiomyocytes firing pattern. 